\title{
Ethnomathematics and Geometrical Shapes in Bedouin Women's Traditional Dress
}

\author{
Abu Qouder Fouze, Miriam Amit \\ Ben-Gurion University of the Negev, Eilat, Israel \\ Email: abuceoud@gmail.com, amit@bgu.ac.il
}

How to cite this paper: Fouze, A. Q., \& Amit, M. (2019). Ethnomathematics and Geometrical Shapes in Bedouin Women's Traditional Dress. Creative Education, 10, 1539-1560.

https://doi.org/10.4236/ce.2019.107112

Received: June 4, 2019

Accepted: July 14, 2019

Published: July 17, 2019

Copyright $\odot 2019$ by author(s) and Scientific Research Publishing Inc. This work is licensed under the Creative Commons Attribution International License (CC BY 4.0).

http://creativecommons.org/licenses/by/4.0/

(c) (i) Open Access

\begin{abstract}
Ethnomathematics asserts that in addition to the formal, academic mathematics which developed in the West, there are other forms of mathematics which developed in many other societies and cultures around the world. Much research and educational experience has shown that combining ethnomathematics with formal mathematics teaching in the classroom improves the achievements of students from various ethnic and cultural groups; it strengthens their self-image and reinforces their motivation for mathematical study and research. This paper aims mainly to offer an ethnomathematical analysis of Bedouin embroidery samples taken from traditional dresses made by Bedouin women from the Negev area in the south of Israel. It also aims to describe how ethnomathematical elements are incorporated in the teaching of mathematics for Bedouin students in the Negev, and how this contributes to their learning of mathematics.
\end{abstract}

\section{Keywords}

Ethnomathematics, Mathematics Education, Fouze, Geometrical Shapes, Bedouin Cultures, Bedouin Embroidery

\section{Introduction}

Ethnomathematics presupposes that mathematics, like many other human endeavors, is the cultural product of human experience; that it may vary from one group to another, and that it depends on social power structures (Terry, 2011). Ethnomathematics began as a topic of academic research during the 1980s by the Brazilian researcher Ubiratan D'Ambrosio, who claimed that the "standard" mathematics generally accepted in Europe and North America is not the only mathematics in existence, and that various social, ethnic and cultural groups have their own kinds of mathematics (D'Ambrosio, 1985). According to this 
view, the traditional way in which mathematics is taught in the West supports the preservation of the social order and power relations of the stronger over the weaker groups within society. Ethnomathematics, on the other hand, allows for the existence of another mathematics whose narratives are rooted in the local and weaker groups in society (Terry, 2011).

As a research discipline, ethnomathematics, which is situated on the borderline between the history of mathematics and cultural anthropology, studies the discipline of mathematics with emphasis on the economic, social and cultural background of its development (D'Ambrosio, 1985).

D'Ambrosio's premise was that there are different forms of thinking in mathematics; that there is "more than one mathematics" (p. 44-48). The basic ways of doing mathematics are a result of measuring, counting, comparing, classifying and deducing, all of which derive from the natural environment in which they develop (D’Ambrosio, 2002).

Academic mathematics, which is composed of organized concepts created and developed around the Mediterranean Basin, became an accepted discipline during the Middle Ages and the Renaissance period (D'Ambrosio, 2016). Ethnomathematics, which developed in various communities in other geographical and cultural milieus, can be seen in the work of the artisans and craftsmen in those communities (D'Ambrosio, 2002). While some use the term ethnomathematics to refer to a specific indigenous culture, D'Ambrosio emphasized that within diverse cultural contexts, techniques and arts evolved which expressed the local way of understanding the environment and that the knowledge categories of ethnomathematics should associated with place, time and community (D’Ambrosio, 2016).

Traditional institutionalized mathematics can be considered Eurocentric (D’Ambrosio, 1985; Powell \& Frankenstein, 1997) and as reinforcing racial, ethnic and gender-related inequality (Anderson, 1990). Traditional mathematics presupposes that the basis of mathematics is not material and that it is not related to economic, political and cultural changes; it asserts that the route to mathematical discoveries passes through the application of deductive logic, which is unique to Greek mathematics.

According to this belief, empirical or intuitive approaches are not relevant to mathematics, and only a few intellectual elites are capable of understanding it. Mathematical results should be presented according to the forms and characteristics decided by the white Greek males of over 2000 years ago, and only the select few, who possess these Eurocentric characteristics, can contribute to it.

The academic expertise of mathematics was based on these premises and beliefs and was replicated through the generations, inadvertently furthering racism and colonialism. Mathematics textbooks did, in fact, mention the contributions made by the Mayans and by the Indians, Africans and Chinese to the development of mathematics, but these contributions were consistently undervalued.

Any deviation from the Eurocentric perspective was seen as eccentric or belligerent, undermining the pure values of rigor and proof (Anderson, 1990). 
(D’Ambrosio, 2016) criticized the "ivory tower" entrenchment of academic mathematics, in contrast to ethnomathematics, which allowed for continuous and rapid changes. In traditional communities around the world, ethnomathematics is not a historical product frozen in time and meticulously preserved. On the contrary, it is dynamic, characterized by new solutions that relate to circumstances, phenomena and issues arising from daily life.

Naturally, much criticism was aimed at ethnomathematics by traditional mathematicians. (Rowlands \& Carson, 2002) raised the question: If ethnomathematics is the study of the various forms of mathematics based on different schools of thought, what then is the status of formal, academic mathematics in relation to it? According to D'Ambrosio's definition, academic mathematics is actually only one concrete form of ethnomathematics, and educational authorities should decide whether teaching ethnomathematics might not be preferable to teaching formal mathematics. Traditional mathematicians believe there is a contradiction between the negative view of ethnomathematics vis-a-vis the Eurocentric Greek tradition, and the positive view of multi-cultural sources of Greek mathematics, including those of ancient Egypt.

Rowlands \& Carson warned against blurring the distinction between ancient local traditions and cultures that must be preserved, and scientific tradition. In response to this critique, (Adam, Alangui, \& Barton, 2003) replied that one should not worry about blurring that distinction; ethnomathematics sheds light on vital and dynamic aspects of the knowledge systems of cultural traditions which are still valuable and valid today. The mathematical ideas developed among non-Western peoples over the years are providing contemporary mathematics with new problems and concepts. Nevertheless, they still come under attack. The strict preference of Eurocentric mathematics is in contradiction to the protection, appreciation and perpetuation of the ways of thinking, knowledge systems and values of indigenous peoples. In contrast, ethnomathematics does not aim to replace academic mathematics or reject the research and knowledge which evolved in the West. It only aims to study and teach various forms of indigenous mathematics, and thus contribute to the development of knowledge in general.

\section{Cultural Backgrounds, the Bedouin Population of the Negev}

The Bedouins are an ethnic group of Arab Muslim nomads. The name Bedouin comes from the Arabic word Badia, meaning desert. Most of the Bedouin population of Israel is concentrated in the Negev area of southern Israel.

These Bedouins came to the Negev from the Hejaz area of Arabia in three main nomadic waves: the first wave was at the time of the rise of Islam in the seventh century A.D.; the second, in the ninth century; and the third, in the sixteenth and seventeenth centuries (Abu-Rabi'a, 2001). The traditional Bedouin way of life differs from that of the non-Bedouin Arabs in Israel. Bedouin society is a tribal, nomadic one; the Bedouin are desert dwellers engaged in farming and 
shepherding.

In 2015, the Bedouin population in the Negev totaled approximately 240,000 , mostly in the northern Negev region. Almost 75\% of the Bedouins live in 18 officially recognized towns and villages, and the rest in non-recognized villages (Myers-JDC-Brookdale, 2017). The permanent Bedouin towns and villages were established by the State of Israel between 1969 and 2004. All of the Bedouin towns and villages in the Negev are classified as belonging to Clusters 1 and 2 of the socio-economic scale (the lowest ones), and in most of them the electricity, water and sewage infrastructures and the public services provided are sorely lacking and direly substandard. The non-recognized villages, located in the north-eastern part of the Negev, do not receive municipal budgets nor do they have any system of local government. These villages are not connected to the national electricity, water and sewage grids, and have barely any public services at all (Ben-Ari, 2013).

The employment rate among Bedouin men is about $60 \%$, and among women, $22 \%$. Such an employment rate is considerably lower than that of the Jewish and non-Bedouin Arab populations in Israel. The high-school dropout rate of Bedouin youth in 2015 was 29\%, significantly higher than that of Jewish and non-Bedouin Arab youth. The rate of Bedouin high-school students who earned a matriculation diploma increased in $2014 / 2015$ to $22 \%$ but this rate is still lower than that of Jewish high school graduates (53\%) and non-Bedouin Arab graduates (38\%). Nevertheless, the rate of Bedouin undergraduate students in 2015/2016 was twice that of 2007 and the number of female students is even higher than that of male students (Myers-JDC-Brookdale, 2017). The overall number of students among the population is low compared to Jewish and non-Bedouin Arab students.

In general, Arab society in Israel is caught in the middle of modernization and cultural individualism, influenced by the surrounding Israeli Jewish society and their own traditional religious values. The community and family find it hard to deal with the gradual social, cultural and ideological changes happening all around them, and the young people especially are influenced by this tension (Abu-Asba, 2008). Bedouin society in the Negev is part of this, and the tensions between modernization and tradition have increased there, too.

The culture and tradition of the Bedouin nomadic lifestyle are in stark contrast to the modern Western Israeli lifestyle and, among other things, this affects the quality of education. The Bedouin elders were, in the past, nomads who moved from place to place in search of water and new pastures; but the younger ones settled in permanent towns and villages and the social, cultural and economic situation of the community has been totally transformed (Amit \& Abu Qouder, 2017). The insufficient infrastructures of Bedouin towns in general and schools in particular, the absence of good teachers, and the lack of high-quality public services are among the causes for the relatively high dropout rate of students from the education system. Yet another significant factor which makes it hard for students to get accustomed to modern, Western-oriented schools is the 
contradiction, even the threat, they pose to the traditional Bedouin way of life and values. This may be another cause for the high dropout rate and the relatively low number of high-school graduates (Amit, Fried, \& Abu-Naja, 2007).

\section{Summary of the Bedouin Population of the Negev}

The new-old story of the Negev and its inhabitants begins in the 4th millennium $\mathrm{BC}$, continues with the Bedouins establishing their residence in the region in the 7th century $\mathrm{AD}$ and, even today, when the main bulk of the Bedouins living in Israel converged in the Negev. Inevitability, development also led to a process of Bedouin transition from nomadic and tribal to a modern urban way of life. The dilemma each Bedouin confronts is far from being simple: how to preserve the tradition and customs passed from generation to generation on one hand, and to adapt and fulfill oneself in modern society on the other.

\section{Ethnomathematics in Education}

Ethnomathematics may be defined through its educational aspect: "Drawing connections between mathematical content and the culture of the learners" (Amit \& Abu Qouder, 2017: pp. 23-50). The traditional role of mathematics education is utilitarian; among other things, it helps graduates of the education system successfully join the labor market. Yet the role of education in the present age has grown beyond that. Education can and should promote children's cultural dignity. This is where teaching ethnomathematics at school can help. Applications of ethnomathematics in education stem from the natural environment in which children grow up in different global communities. Ethnomathematics is as dynamic as language, medicine, fashion, cookery, values and religion. It allows one to recognize the diversity and dynamism of different knowledge systems and teaches children to develop tolerance, acceptance of the other, and an egalitarian approach to life.

Traditional mathematics in education reflects social and political power. Ethnomathematics in education allows a "politically correct" approach which lessens discrimination and inequality and promotes social change (D'Ambrosio, 2002). Some researchers claim that ethnomathematics does not advance the students' knowledge of traditional mathematics (Rowlands \& Carson, 2002); but the uniform conventional teaching of mathematics does not suffice to enrich our knowledge of cultures. Teaching ethnomathematics prepares students from diverse social groups for acquisition of mathematical knowledge of a different sort, one which is related to the culture and traditions of their upbringing (D’Ambrosio, 2002).

During the years since its inception, the ethnomathematics approach has become popular and acceptable in mathematics teaching across the United States (Rowlands \& Carson, 2002). Despite the many objections to adding ethnomathematics to school curricula-which came mostly from schools that denied there was a problem in teaching mathematics and preferred to continue teaching 
"real mathematics"-over time, ethnomathematics has been added to the curricula of many schools. This stems from the need to make mathematics accessible and understandable to all students (Bishop, 1994).

Adding the ethnomathematics perspective to mathematics teaching allows students from diverse ethnic backgrounds to improve their understanding and learning in several ways, which include: learning through a context which the students regard as having relevance for them; introducing the first stages of mathematics education as part of a world which is close to the child; and providing a new discipline, separate from conventional academic mathematics, that looks at decorative geometrical shapes in weaving, embroidery, sculpture and architecture.

This blend of concepts and experiences from the students' cultural environment, combined with conventional mathematics, helps them grasp its beauty, power and usefulness (Adam et al., 2003). For example, students who learned mathematics through the ethnomathematical roots of their own culture discovered that they knew more than what was revealed by formal tests. Discovering the link between geometrical shapes and everyday objects raised questions about why these shapes were chosen and what they represented; with further investigation and learning, the students felt empowered and their self-esteem grew (Powell \& Frankenstein, 1997).

Many empirical studies have dealt with ethnomathematical knowledge among populations with no formal education. (Gerdes, 1997) reviewed studies on ethnomathematics from North America and Europe, South America, Asia, Australia and Africa, and provided several examples: methods used by Brazilian peasants to measure land, and conceived to be wrong by academic mathematical standards, were proven correct after careful interviews with them; illiterate female market peddlers in Mozambique and peasants in Nigeria proved their ability to perform addition, subtraction and multiplication. Over 100 studies dealing with educational ethnomathematics have been carried out since 2005 in Mexico, Brazil, Mozambique, Morocco, South Africa, New Zealand, USA and many other countries, and demonstrated its contribution and importance to mathematical education. Other studies focused on the conceptual, cognitive, political, social and historical aspects of ethnomathematics and their educational influence (Maxwell \& Chahine, 2013; Alangui \& Rosa, 2016). Many empirical studies point to the improved achievements of students from diverse ethnic and cultural backgrounds in mathematics tests after taking part in an ethnomathematics program. Other studies have shown that using ethnomathematical practices from the learners' cultural world and introducing them into the academic mathematics curriculum helped students understand formal mathematical principles through curiosity, interest and fun (Amit \& Qouder, 2017a). The conclusions from these studies and the experience gathered by teachers using ethnomathematics in their classes can be transferred to traditional curriculum content and classroom activities. Using "cultural mathematics" can enrich the lessons and also, perhaps, affect policy changes dealing with the teaching of mathemat- 
ics. In many countries, the students represent diverse ethnic and cultural backgrounds, and mathematics classes can be made exciting to them through the use of mathematical content relevant to their background (Lawrence \& Palhares, 2016).

Several studies have emphasized the link between geometrical elements of traditional embroidery and ethnomathematics. (Maxwell \& Chahine 2013), for example, showed that symmetrical designs in Moroccan embroidery pieces indicate complex and precise spatial perception and a high level of skills developed over generations. (Abbacan-Tuguic, 2016) analyzed geometrical motifs and symbols in embroidery work created by the Ikalinga tribe of eastern India in which horizontal lines, linked triangles, and zigzag patterns represent the mountainous environment of the tribe and the terraced farming on the mountain slopes. This researcher claims that viewing and analyzing such embroidery pieces in lessons on the basic concepts of geometry can improve the teaching methods and the learning environment in mathematics classes.

The educational benefits that result from combining ethnomathematics and academic mathematics teaching can be summarized as follows: it helps students overcome cognitive difficulties in learning formal mathematics; promotes creativity and problem-solving in mathematics; stimulates motivation and curiosity; enriches students' knowledge of their cultural heritage; supports the formation of a cultural identity; and promotes multicultural awareness and openness (Verner, Massarwe, \& Bshouty, 2013).

Studies done in Arabic high schools in Israel showed that teaching geometry through culturally significant designs stimulated emotional and heated discourse among the students, while boosting their ambition to investigate and study their cultural heritage (Massarwe, Verner, \& Bshouty, 2010). A study of the teaching tactics of trained math teachers from various sectors of Israeli society has shown that using a teaching technique based on ethnomathematical practices helped create a new impetus for learning mathematics. It also altered students' motivation-from one based on an external, comparative reward-to one based on enthusiasm and satisfaction achieved through problem solving (Verner et al., 2013). Amit \& Qouder's (2017a) study demonstrated that a mathematics curriculum involving ethnomathematics in Bedouin high schools contributed to motivation and self-image but did not lead to an immediate improvement in the standardized tests. However, the experience gained in Israel in developing and utilizing mathematics curricula combining ethnographic elements from the students' daily life, such as folk stories, games and crafts, revealed some improvement in their academic achievements (Amit \& Qouder, 2017b).

\section{Ethnomathematics in Bedouin Tradition and Mathematics Education for Youth}

Bedouin culture reflects desert life and the connection of Bedouins in the Negev to their environment. While men built homes and tents, dug wells and shepherded their livestock, in keeping with the nomadic way of life, the women re- 
mained at home. Bedouin families were usually poor, and the women were responsible not only for the children, tent maintenance and food, but also for the sheep and cattle. In their free time, while shepherding, or at night, when the children were asleep, Bedouin women would sew clothes, embroider and weave decorations for the homes and tents. Each woman passed on the skills of embroidery to her daughters, from one generation to the next. In this way, over the years, Bedouin society maintained its values, knowledge and traditions.

Bedouin embroidery is the unique trademark of all Bedouin tribes living in the desert. The families within the tribe shared their lives, and despite the harsh way of life, they cooperated and helped each other. The women would meet, sit together in the tent or while tending the sheep, chat and embroider, while also maintaining a sort of competition between them; who embroiders the fastest, the nicest or with the most stitches. They developed their know-how and skills from early childhood, nurturing them through generations, and despite the hardships, they managed to preserve their unique values and heritage until today.

(Amit \& Qouder, 2017a) studied ethnomathematical elements within Bedouin society in the Negev in order to develop teaching units based on integrating such elements into the mathematics curriculum and evaluate its influence on the students. Their study comprised five stages: the first stage identified ethnomathematical elements in the life of Bedouins in the Negev through interviews with community elders; the second stage analyzed these elements according to formal mathematical categories. In the third stage, the researchers created teaching units incorporating the ethnomathematical elements identified in the initial stages into the standard mathematics curriculum and the fourth stage saw the application of the combined teaching units in two Bedouin high schools. Finally, in the fifth stage, tests were run and data compiled in order to evaluate and compare the students' achievements in solving mathematical problems (as well as the influence of the new teaching units on the self-confidence and attitudes of the students), compared to a control group.

Ethnomathematical elements linked to two-dimensional geometry were identified in embroidery, and three-dimensional geometry was reflected in the design of the traditional Bedouin tent. Ethnomathematical elements relating to measurements were collected through conversations and interviews with 35 men and women, elders of one of the Negev tribes. For example, the units of length used by the interviewees were: "Arm"- the distance between the elbow and the fingertips; also "finger" and "fist". Another unit was the "throwing distance of a stick", meaning a shepherd's stick, or the "throwing distance of a stone", which actually meant the distance walked by the cattle during one day, before dark. This last unit of distance is between 3 and 7 kilometers. The units of weight used by the Bedouins were seen as more accurate than the units of length, and their values were agreed on. For example, the basic weight unit is a wakeh, or 250 grams. Another common unit is a retel, which equals $3 \mathrm{~kg}$., and d'alo, or the amount of wheat required to fill a bucket. There are many other units of length 
and weight.

The participants in the second stage of the study were 175 seventh-grade middle school students; 70 were in the control group, which studied the standardized mathematics curriculum, and 75 were in the research group, which included ethnomathematics in the study of measurements and weights. For the latter group, the teaching units based on these elements were applied to mathematical problems which the students had to solve using both standard and traditional measurement units. The results were then compared. The findings clearly demonstrated an increase in the motivation, self-confidence and enthusiasm of the research group students compared to the control group, which did not exhibit any significant change. The way the research group students perceived their home, family, school and the study of mathematics was transformed. Yet there was no difference between the research and control groups from the standpoint of the students' achievements on standardized Ministry of Education mathematics tests (Amit \& Qouder, 2017a).

\section{Youth Mathematics Club-Kidumatica}

The mathematics club for youths, Kidumatica (literally, "promoting mathematics") was established in 1998 at Ben-Gurion University of the Negev by Prof. Miriam Amit, as a program for teenagers from Beer Sheba and its environs who come from diverse socio-economic groups and ethnic and cultural backgrounds. This program was created to promote interest in mathematics, mathematical thinking, intellectual excellence and creativity among students, and establish a community of "mathematical thinkers" by challenging talented teens to develop and advance themselves in order to become future leaders.

In its first year, Kidumatica had 60 students, male and female; today it has a membership of over 500 students, aged 10 to 17, from 70 Jewish and Arab schools in the Negev. Many students come to the club, situated on the university campus, once a week by bus from places such as Lakiya and other Bedouin communities, and Jewish towns such as Kiryat Gat, Mitzpe Ramon Ofakim, Netivot, Yerucham and Dimona, as well as the Besor district and the area bordering the Gaza Strip. Students participate in short "mini-courses" taught by lecturers who specialize in developing mathematical thinking, on various topics such as "Logical problems", "Mathematics in real life", "Mathematical games", "Fractals", "Joint problem-solving", etc.

In addition, the club runs intensive Activity Days, in which students take part in math contests, write the club magazine together, and attend guest lectures. The group also goes on scientific trips to research institutes and even attend national mathematics competitions. Each group of students is accompanied by a university student who acts as their mentor, giving them academic and emotional support. Prof. Amit and other staff from the Department of Scientific and Technological Teaching at Ben-Gurion University in the Negev also accompany the group (Kidumatica for Youth, 2017; Amit et al., 2007). 


\section{Ethnomathematics at the Kidumatica Club}

Kidumatica Club, the first program of its kind in Israel, fosters mathematical excellence among Bedouin teenagers and works with both Jewish and Arab students. The percentage of female Bedouin students is high-over $40 \%$. The Bedouin students are highly committed to the program; their attendance rates are higher than those of the other groups and their dropout rate is negligible, despite the physical difficulties in reaching Beer Sheba. The program's success is reflected in the Bedouin students' high level of commitment and their successful integration with other students, all of whom excel in mathematics (Amit et al., 2007).

The author of this paper started teaching in the Kidumatica Club in 2015, as a doctoral student whose thesis is about ethnomathematics among the Bedouin community of the Negev. he teaches three groups each composed of 25 - 30 seventh- and eighth-grade students, from Lakiya and other Bedouin villages, and introduces them to ethnomathematics-mathematics from a wholly new, different angle-and to the bond between mathematics and the Bedouins in the Negev. Here are some examples of the ethnomathematical activities the Bedouin students enjoy in the club:

Bedouin embroidery - the patterns Bedouin women add to their embroidery are called "toub"-_الثوب البدوي". These are geometrical shapes, yet the embroiderers never knew they were related to mathematics. The embroidery is done in stages, and all the shapes are identical, which allows for a high level of precision and beauty. The women learned their craft from their mothers, who learned it from their mothers, and so on. The students are surprised to learn that "what granny embroiders" is not just pretty shapes but also "real mathematics", and that Bedouins are connected to mathematics.

Mathematical games_the men used to play "Alsidja"_ “"عبة السيجه". This game is based on numbers and is quite similar to draughts. One needs to be highly intelligent to win at it. The students play the game in pairs and apply what they have learned. The classes that involve ethnomathematics have a great influence on the students. They enjoy themselves, love studying this subject and are curious to know more. Their sense of pride in being part of the Bedouin heritage grows.

\section{Ethnomathematics in Bedouin Embroidery}

This chapter offers an analysis of six examples of traditional Bedouin embroidery in order to identify the geometric patterns and components of those embroideries. The embroidery patterns in images $1-6$ are taken from traditional dresses sewn by the author's mother for his grandmother before she passed away. The author's mother learned traditional embroidery techniques from her mother (the author's grandmother) fifty years ago.

Contemporary Bedouin women no longer wear the "toub" al embroidery-rich Bedouin dress, and only the tribe's elderly women, aged 60 and over, wear them nowadays. As a result, very few women continue to engage in traditional embroidery. Despite all the influences of modernization on Be- 
douin society, most families in the Negev still maintain tradition. In nearly all families there are still women who continue to embroider, especially families whose older-generation grandmothers are still alive. In such families, the girls embroider the "toub" for their granny, who has taught them to embroider at an early age. In more modern families, there are women who learned how to embroider from their mothers, and still do it and wear dresses with Bedouin embroidery out of respect for their faith and cultural awareness.

For example, the author's aunt does not give up wearing her traditional Bedouin garb because she believes in the Bedouin social values. It seems that the tradition of embroidery is going to stay in Bedouin society, and, despite modernization, will carry on into the future. The "toub" on the dress was divided into parts, each with its own name: the embroidery on the front and back parts is called "sayuf"-سيوف; the top front side is called "koube"-القبه; and the embroidery on the arms is "erdan"- الردان.

The embroidery work was very precise, so that each shape within the pattern was equal and identical to the one beside it. The embroiderer would measure the length and width in a way that allowed her to be precise and reach her desired result, where all shapes are identical and create precise symmetrical patterns.

The embroiderer would use a "marka" - ماركة. The "marka" is a piece of white material divided into a mesh of tiny squares that make it possible to measure the size, length and width of each shape in the embroidery. The "marka" was placed on the material before starting the work, and so remarkably precise embroidery was possible.

\section{Analysis of Embroidery-Examples}

\subsection{Example: 1}

The "toub" in the example is rectangular around the neck and chest. The "toub" is made of a symmetrical design on both sides of the neck opening, and downward, on both sides of the midline, crossing the pattern vertically. The patterns on both sides of the neck opening are identical in both geometrical design and colors. Two lines create a boundary around the top part: a purple line made of $\mathrm{X}$ shapes around the neck opening; and a perimeter line of Xs around the purple line and on the top part of the "toub" at the chest. Under this boundary line there are 7 symmetrical diagonal lines on each side, starting near the neck, and 7 other symmetrical diagonal lines starting near the sleeve. These lines are imagined, since they are made of parts of the $\mathrm{X}$ shapes.

The diagonal lines on both sides of the "toub's" top part create a pattern of a grid of diamonds. Each internal diamond shape of that grid has two small flowers in various colors; the crossing points of the diagonal lines show green leaf shapes. Thus, an impression is created of a rich, colorful grid of flowers and leaves inside a grid of diamonds. An imaginary midline separates the grid of diamonds on the top part of the "toub" from its bottom part. Around that area there is a zigzag line which seems to continue the diagonal lines from the top part. The zigzag line creates a pattern that looks like triangles missing a baseline. 
Inside each imaginary triangle, there are the same flower shapes as in the top grid of diamonds, and around the angles of the triangles toward the internal part of the dress, the same leaves appear as in its top part. This way, the same design motif is maintained throughout the chest part of the "toub".

The internal bottom part of the chest "toub" has a different pattern. $12 \mathrm{di}$ agonal $\mathrm{X}$ lines colored yellow-beige, green and purple, parallel to each other and embroidered one next to the other, create two thick and symmetrical diagonal lines which meet along the vertical midline of the dress. Between those two lines, another black line is created from the dress material. The thick diagonal lines create two inverse triangles whose base is the imaginary line created by the edge of the grid of diamonds in the top part. The inside of the top inverse triangle has 5 shapes of colorful stars, with a pattern of flowers and leaves embroidered between the lines, symmetrically, on both sides.

Along the whole front of the dress a large rectangle is created out of two long parallel lines, top to bottom, in various colors. Two additional lines on the inside part are made of a repeated pattern of flowers and leaves embroidered on both sides of a wave-like line along the whole dress. That pattern is also repeated symmetrically on both sides of the dress, along the boundary line between its front and back. The geometrical lines and shapes found within the patterns of this dress are: long, straight and wave-like lines; broken lines the shape of Xs; zigzag, diagonal lines in both directions; rectangles, diamonds, triangles and star and flower shapes.

The mathematical and geometrical values in the "toub" design make it possible to use geometry to teach types of lines-straight and bent, diagonal and broken; the characteristics of a rhombus (diamond) and isosceles triangle; and also for teaching counting, addition and subtraction in mathematics (Figure 1 and Figure 2).

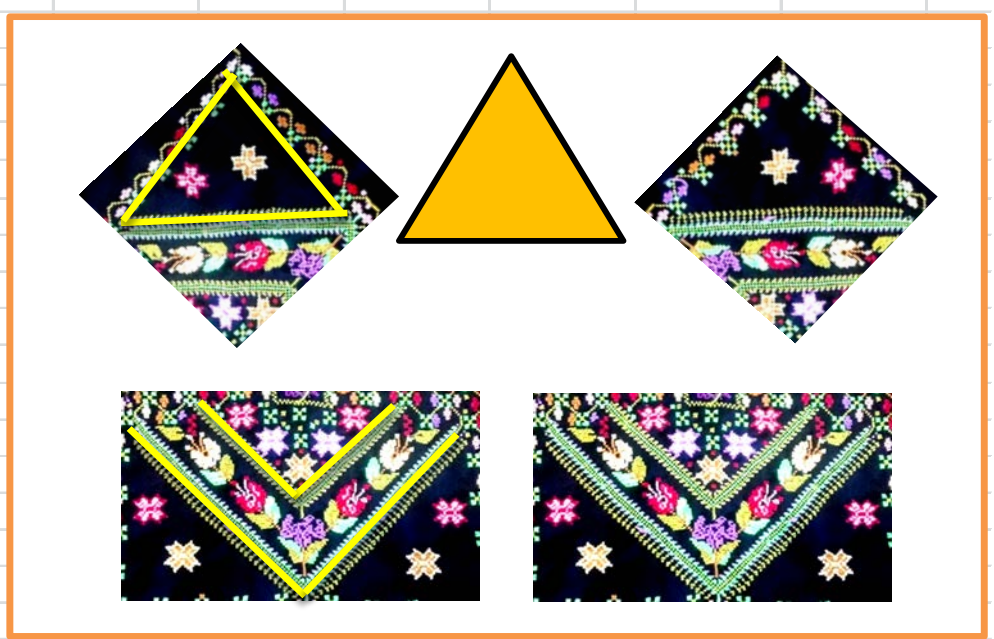

Figure 1. Shows the braid pattern is bordered from all directions by zigzag-shaped broken lines which create imaginary base-less triangles whose vertices turn up or down intermittently. The zigzag lines create a rectangular shape around the whole internal part of the "toub". 


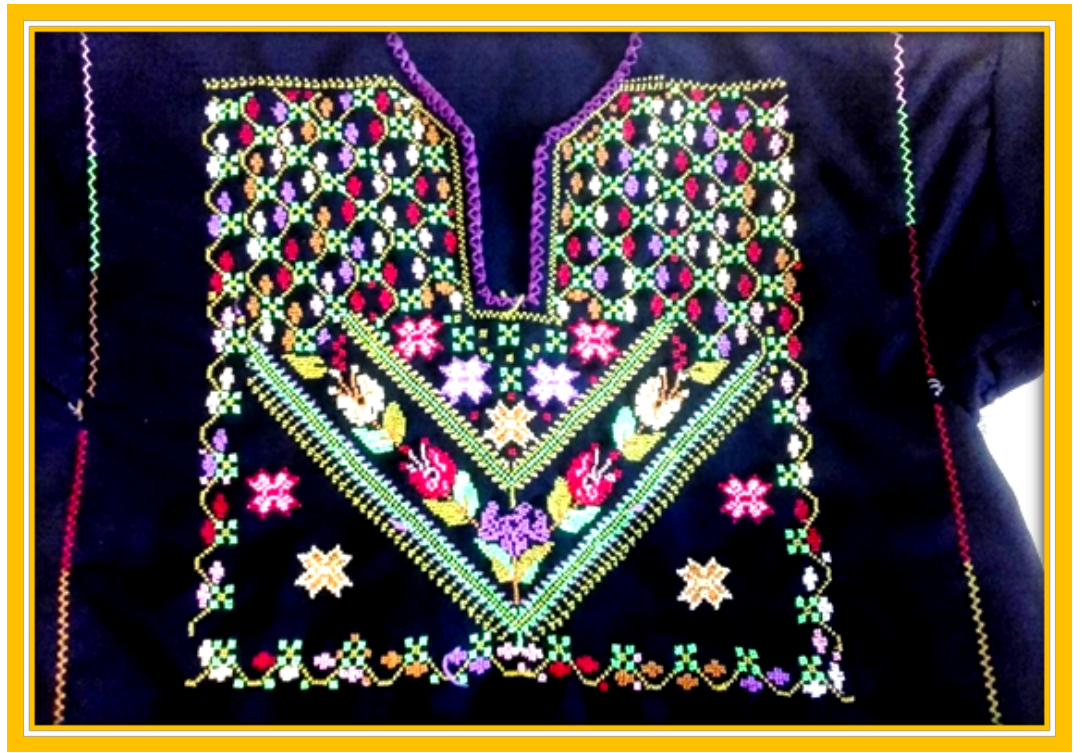

Figure 2. Show chest part of dresses (toubs).

\subsection{Example: 2}

The "toub" in the chest part of the dress is rectangular. Around the neck opening of the blouse there are embroidered lines in several colors, close to one another, which create a border for the area around the neck and top chest. Below these lines one can imagine a vertical midline going down to the "toub's" bottom edge. The embroidery is symmetrical on both sides of the midline. A series of repeated wave-like lines, each pair starting at the bottom part of the "toub" in different directions, are entwined to create a braid pattern. This way three braids are created on each side, symmetrically, on both sides of the vertical midline. The shapes inside the internal part of the braids are placed symmetrically around an internal cross to create four shapes that look like four triangles whose vertices meet, yet their bases are not really straight.

These bases, bordered by the braid-like lines, each turn towards a different direction. The braid pattern is bordered from all directions by zigzag-shaped broken lines which create imaginary base-less triangles whose vertices turn up or down intermittently. The zigzag lines create a rectangular shape around the whole internal part of the "toub".

Two additional long vertical lines frame the whole "toub" area. These lines start at the top of the dress and connect to a horizontal line at the bottom to create a rectangle. Additional parallel vertical lines in intermittent colors are located on both sides of the dress, and a horizontal line decorates its bottom edge. There are flower designs adorning the dress from the internal part of the vertical lines and along its borders, on the line separating its front and back, and on its sleeves.

The geometrical and mathematical values in this example make it possible to use it to teach contiguous and broken lines; rectangles and squares; triangles and angles; and also for teaching counting, addition and subtraction in mathematics (Figure 3 and Figure 4). 


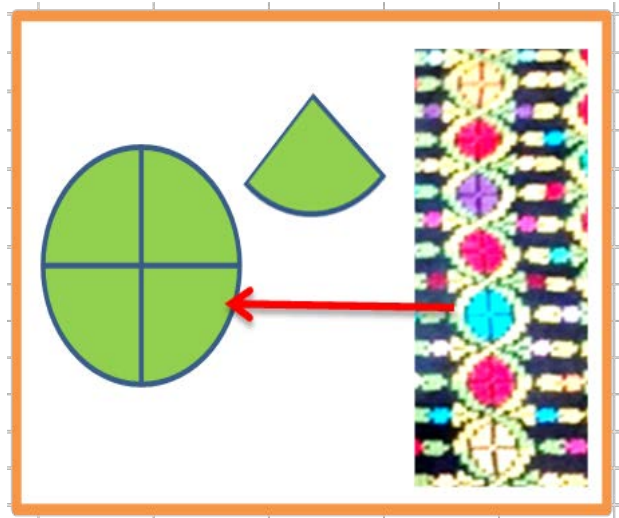

Figure 3. Shows the four triangles whose vertices meet, yet their bases are not really straight.

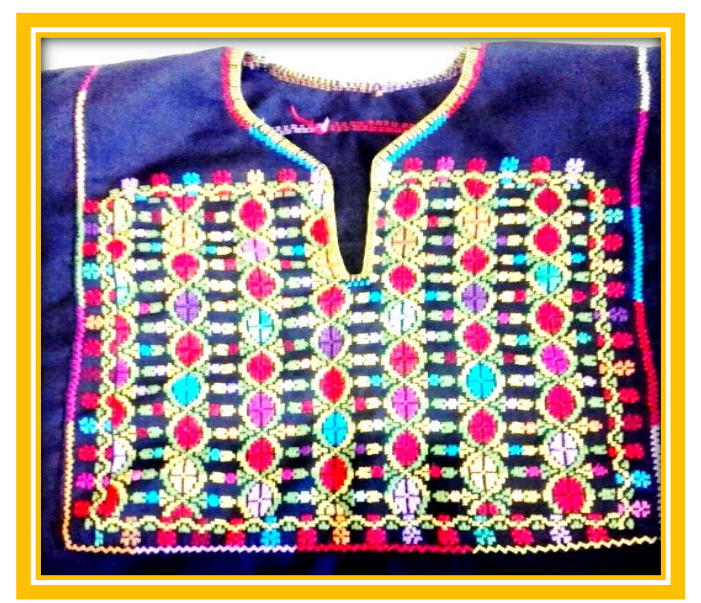

Figure 4. Show chest part of dresses (toubs).

\subsection{Example: 3}

The "toub" in this example is square-shaped. Its borders are embroidered with shapes of stems, leaves and flowers. The flowers' petals are star-shaped. The dress's neck opening is the shape of a rectangle with its top missing. The embroidery around the neck opening creates the external borders of this rectangle through a straight line, as well as a flower motif in curved lines. An imaginary vertical midline goes down from the neck opening to the flower motif at the bottom of the rectangle. Diagonal lines on both sides of the vertical midline meet below to create the vertex of a triangle. The diagonal lines on both sides are parallel.

A straight line and a broken zigzag-shaped line underneath; three more straight lines and one more broken zigzag-shaped line; and another straight line create an identical pattern of diagonal lines on both sides.

The internal part of the triangle creates a frame in whose center a diamond hides. The diamond has eight additional ones, each pointing in a different direction, creating a star that looks like a flower. Over this diamond there's another design of eight diamonds each in a different direction, creating another star over 
the diamond. Additional symmetrical flower shapes facing in different directions complete the dress' "toub".

The mathematical values and geometrical shapes one can learn through this example are: parallel, straight and broken lines and shapes such as squares, diamonds, stars, angles, etc. It can also be used for teaching counting, addition, subtraction and multiplication in mathematics (Figure 5 and Figure 6).

\subsection{Example: 4}

The "toub" in the chest area of this dress creates a square-shaped pattern made of straight internal lines arranged within a grid of diagonals. Nine straight diagonal lines with their top edge on the left, cross nine other straight diagonal lines whose top edge is on the right. This way, a pattern is made of a grid of diamonds. Around the "toub" there exists a frame: two horizontal frame lines, on

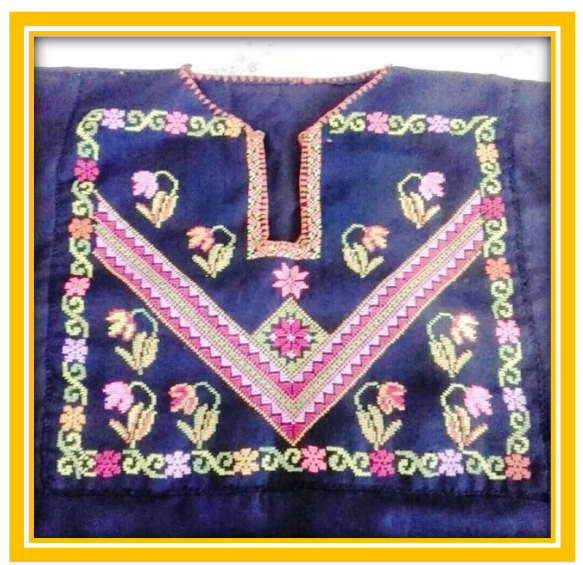

Figure 5. Show chest part of dresses (toubs).

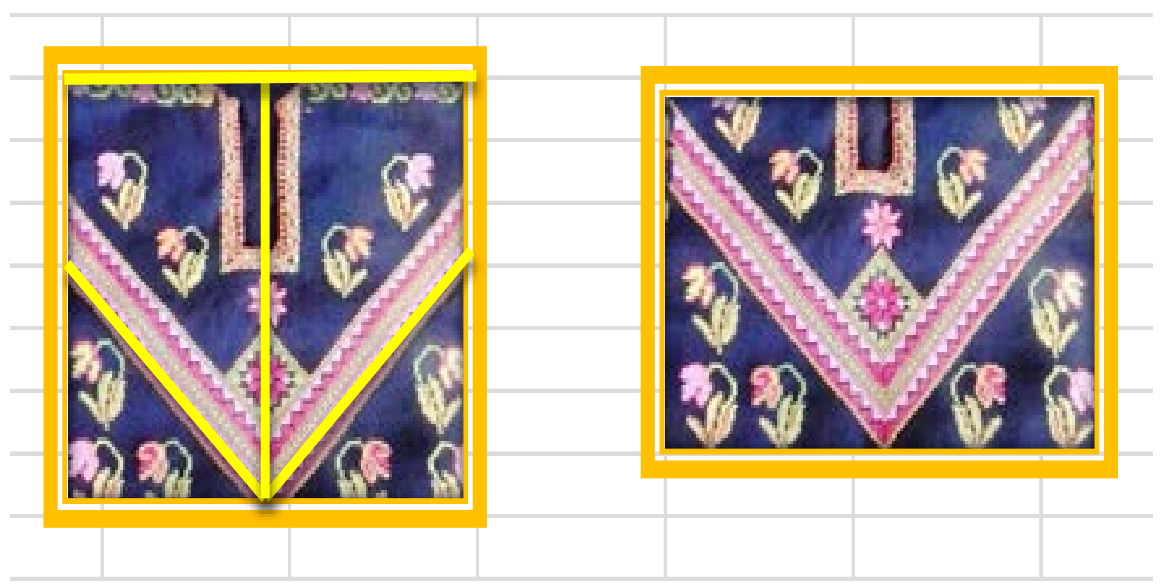

Figure 6. Show chest part of dresses (toubs) that the dress's neck opening is the shape of a rectangle with its top missing. The embroidery around the neck opening creates the external borders of this rectangle through a straight line, as well as a flower motif in curved lines. An imaginary vertical midline goes down from the neck opening to the flower motif at the bottom of the rectangle. Diagonal lines on both sides of the vertical midline meet below to create the vertex of a triangle. The diagonal lines on both sides are parallel. 
the top and bottom, are parallel to each other and along with two vertical parallel lines, create the ribs of a square. Each diamond in the grid has a flower shape inside. That flower is made up of smaller colorful diamonds.

Six small diamonds are attached at their vertices and facing in different directions together create a star shape, seen as a flower from afar. This way, diagonally arranged flower shapes are created on both sides of an imaginary vertical midline. The embroiderer used colors to make up lines of flowers in light blue, dark blue and purple, which create diagonal and symmetrical patterns on both sides of the midline, inside the grid of diamonds.

The chest "toub" is at the center of the dress, on both sides of the neck opening. Two additional vertical lines, which are straight all the way to a point in the chest, where they break, create a rectangular pattern along the whole dress. In the inner sides of the vertical lines and parallel to them, there are straight lines made out of an internal wave-like line with light blue and purple flowers and leaves embroidered on its sides.

This example can serve to teach straight, contiguous and broken lines, wave-like lines, diagonals and grids, squares and rectangles, diamonds and triangles; and various angles. It can also be used for teaching counting, addition, subtraction, multiplication and division (Figure 7 and Figure 8).

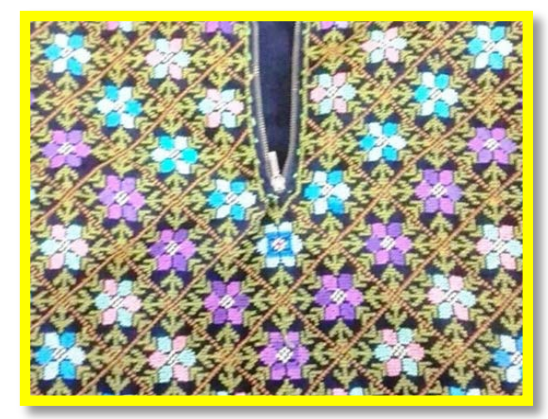

Figure 7. Shows the chest part of (toub).

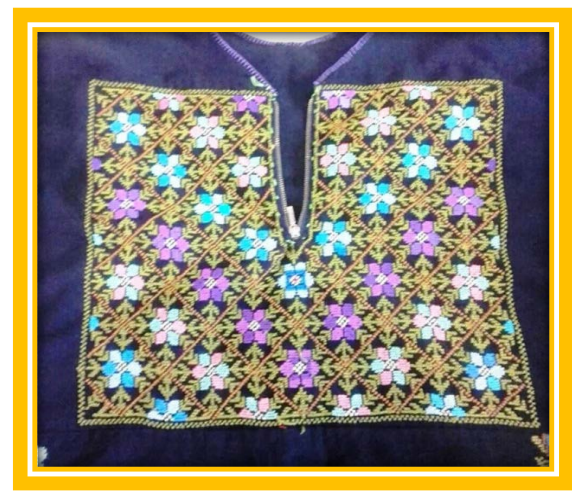

Figure 8. Show chest part of dresses (toubs). We can see around the "toub" there exists a frame: two horizontal frame lines, on the top and bottom, are parallel to each other and along with two vertical parallel lines, create the ribs of a square. Each diamond in the grid has a flower shape inside. That flower is made up of smaller colorful diamonds. 


\subsection{Example: 5}

The "toub" in this example is designed as a rectangle around the neck opening with inverse triangles inside, made up by symmetrical, diagonal lines. The diagonal lines go down on both sides of an imaginary vertical midline. The diagonal lines on each side are parallel, so each side has a pattern of thick and narrow lines which frame the inverse triangles. The baseline of these triangles is missing, but may be imagined

Both sides of the neck opening have shorter vertical lines. Each side has six parallel, symmetrical lines of variable lengths on both sides. Along each line there are flowers embroidered in a shape similar to a diamond. Each flower is made up of four smaller ones, which create the petals around an internal diamond that represents the calyx at the center of the flower. This way there are seven flowers on each side of the neck opening, which are also symmetrical in their colors. Within the triangles in the "toub's" bottom part, between the lines making up the triangle ribs and below them, too, there are flowers of different sizes. The smaller flowers at the top part of the dress slowly turn into larger ones. The flowers are placed inside the triangles, and at the dress's bottom part they sit along shorter straight, brown lines which represent a stem. They are repeatedly intertwined with small and large leaves which fill the "toub" creating a sense of movement.

This image can teach students about long, parallel and straight lines; squares, diamonds and triangles; and mathematical values such as counting, addition, subtraction, multiplication and division (Figure 9 and Figure 10).

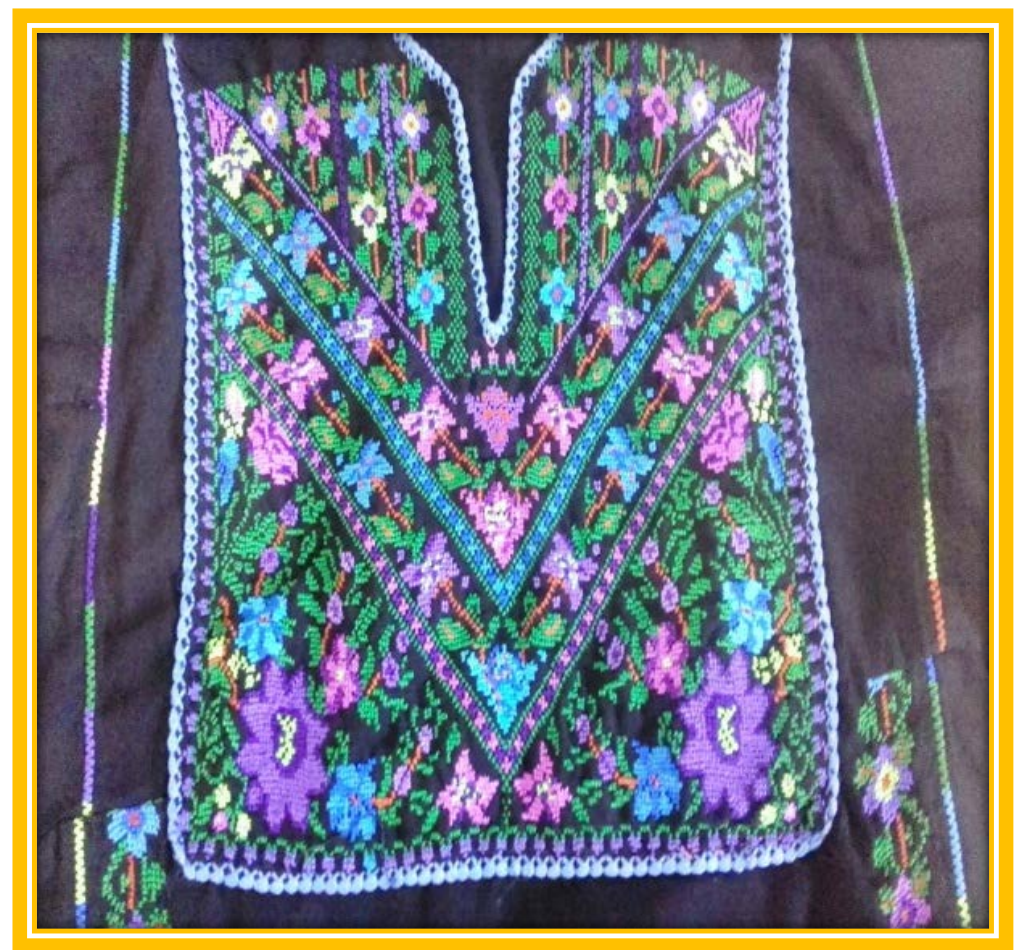

Figure 9. Show chest part of dresses (toubs). 


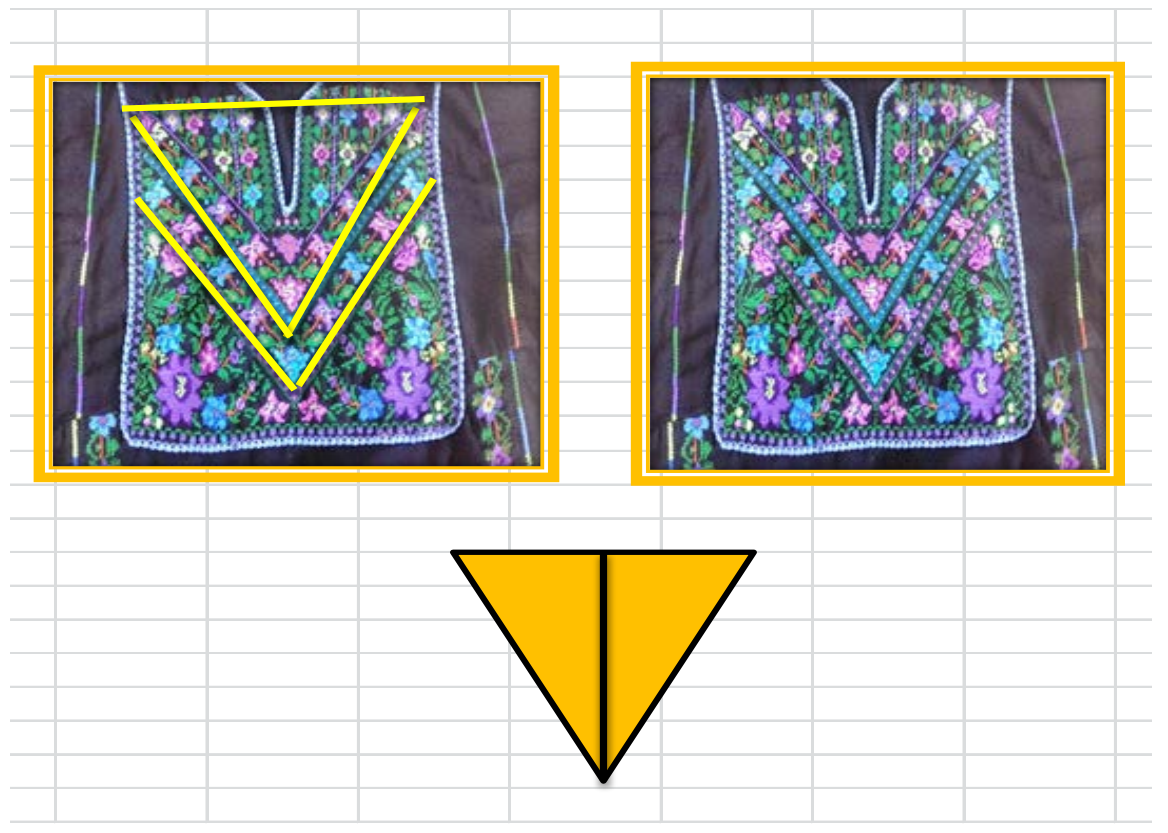

Figure 10. Show chest part of dresses (toubs). We can see a rectangle around the neck opening with inverse triangles inside, made up by symmetrical, diagonal lines. The diagonal lines go down on both sides of an imaginary vertical midline.

\subsection{Example: 6}

This is a particularly interesting example, since it is taken from a white, not black, dress which is embroidered nearly throughout with flower designs. This can be seen on both sides of the geometrical pattern at the bottom of the dress. The "toub" at the bottom of the dress is made up of the same colors of the flower designs, and can be seen as a kind of palette.

The flowers in this dress are embroidered as round, non-geometrically defined shapes. Each flower has its own unique shape. Yet the flowers together create symmetry along both sides of an imaginary vertical midline. The lines connecting the flowers are short curved ones, which look like stems.

The "toub" at the center of the picture is made up of parallelograms, one on top of another. The pattern has four vertical lines, each made of six pairs of parallelograms whose vertical ribs are connected. Each pair of parallelograms is in a different color, and that way another shape is created, reminding one of a roof. These shapes are arranged one on top of the other, and seem to "sit" each on top of the other, thus creating the vertical lines. Yet, unlike the other examples, we have seen, the colors of the pairs of parallelograms are not arranged symmetrically, and the wallpaper pattern created seems interesting and even somewhat abstract. The combination of colors, large and small flower shapes, stems and the geometrical shapes of parallelograms creates a colorful, cheerful and celebratory feeling. From this example, one can learn about straight and curved lines, parallel lines, parallelograms and angles, and counting, addition and subtraction (Figure 11). 


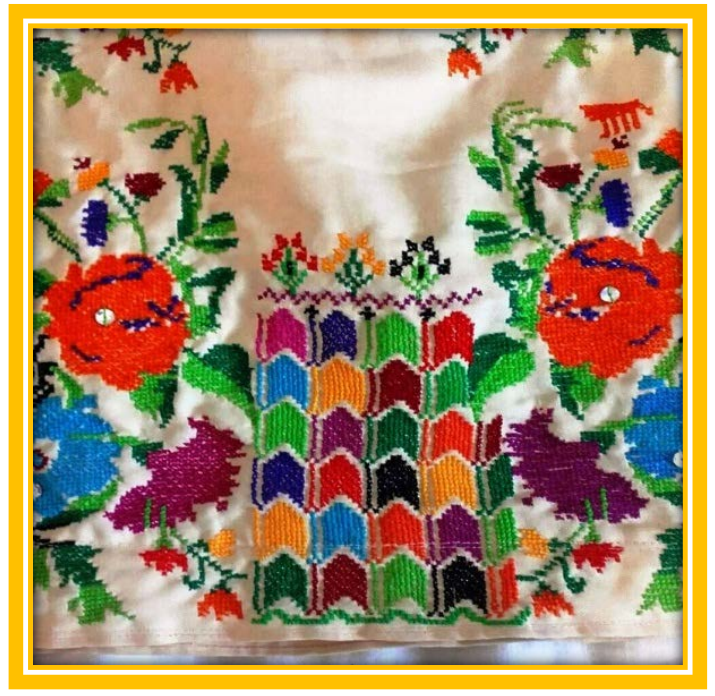

Figure 11. Show part of the dresses (toubs). In this picture appears the shape of the parallelogram.

\section{Conclusion}

Following the development of the ethnomathematical trend as an educational-cultural field, several proposals were suggested and numerous attempts were made to develop curricula with multicultural mathematical ideas that include traditional cultural values, traditions, symbols, and mechanisms for the purpose of aiding the instruction of mathematical subjects. This trend testifies to the importance and centrality of ethnomathematics, which appears now not only as a matter of enrichment or the property of a certain society of power, but as a matter that requires an overall effort to develop. Therefore, cultural values must be utilized in mathematical education and instruction, out of solidarity and respect for all cultures as such, while preserving their future existence (Shirley, 2001).

According to D'Ambrosio (2002), educators are responsible for the learning process and therefore they must develop informal curricula that refer to the reality in which the student lives, while integrating traditional values in their cultural-educational context in the mathematical instruction and learning process. As he stated:

"Education must impart respect of culture and take into account cultural values. This matter requires much more than is offered in the regular curriculum. The situation of math is particularly grave. It has no relation to the experience of children. We need more mathematical content that creates interest" (p. 3-5).

Teaching mathematics without cultural context on the pretext that it is abstract and universal is the reason for the failure of students in this subject. On the other hand, when students are exposed to various cultural links and reflect upon them together, they develop a desire to learn and their self-confidence grows.

A similar result was found in a research we conducted and that included the development and implementation of an ethnomathematical curriculum among 
two groups of Bedouin students in Israel (Amit \& Qouder, 2017a).

"Comparisons between the experimental group (75) and the control group (70) showed that studying the integrated curriculum improved the students' self-perception and motivation, but had almost no effect on achievements in school tests that were conducted immediately after the experiment. The experiment had an extra social impact, changing students' attitudes to their own culture and the tribe's older generation" (Amit \& Qouder, 2017a).

The main idea behind ethnomathematics is that mathematics does not belong only to the Eurocentric West, and that non-Western cultures have their own kinds of mathematics. Traditional Bedouin embroidery demonstrates once again that the basic mathematical principles had been known and used on a daily basis, in societies and cultures far away from Europe. As demonstrated by the studies reviewed in this paper, incorporating ethnomathematics into the teaching and learning of mathematics by Bedouin students reinforces their self-confidence, their bond with their families, their curiosity and their motivation to study mathematics through helping them to appreciate their tradition and culture.

This analysis of embroidery samples from Bedouin dresses illustrates the rich diversity of geometrical lines and shapes built symmetrically and accurately into different patterns and designs. The impression one gets from these examples is that of repeated movements of shapes laid out beside and inside each other to create a complex, colorful image which interweaves all the small details into perfection and beauty.

Bedouin women did not use accurate instruments of measurement, nor did they know the rules of formal academic geometry. Yet these embroidery examples reflect an intuitive knowledge of the multiple lines and shapes of geometry, and a wondrous ability to interweave these small details into larger shapes. Traditional knowledge, passed on from mother to daughter through the generations, allowed Bedouin women to create such complex works accurately, meticulously and creatively. The smaller shapes had to be counted perfectly, in order to create a precise symmetry along both sides of a vertical or horizontal straight line. An in-depth examination of these examples reveals more and more hidden geometrical shapes that keep revealing even more complex shapes.

\section{Conflicts of Interest}

The authors declare no conflicts of interest regarding the publication of this paper.

\section{References}

Abbacan-Tuguic, L. (2016). Mathematics of Folk Art: The Geometric Motifs in the Embroideries of Ikalinga. International Journal of Advanced Research in Management and Social Sciences, 5, 816-829.

Abu-Asba, H. (2008). Arab Youths in Israel in the Turmoil of Social-Cultural Change. In A. Reches, \& A. Rodnitzky (Eds.), Arab Youth in Israel: Between Opportunity and Risk 
(pp. 19-22). Tel Aviv: Moshe Dayan Center for Middle-Eastern and African Studies, Tel Aviv University. (In Hebrew)

Abu-Rabi'a, A. (2001). A Bedouin Century: Education and Development among the Negev Tribes in the Twentieth Century. New York: Berghahn Books.

Adam, S., Alangui, W., \& Barton, B. (2003). A Comment on: Rowland \& Carson "Where Would Formal, Academic Mathematics Stand in a Curriculum Informed by Ethnomathematics? A Critical Review". Educational Studies in Mathematics, 52, 327-335. https://doi.org/10.1023/A:1024308220169

Alangui, W. V., \& Rosa, M. (2016). Role of Ethnomathematics in Mathematics Education. In M. Rosa, U. D’Ambrosio, D. C. Orey, L. Shirley, W. V. Alangui, P. Palhares, \& M. E. Gavarrete (Eds.), Current and Future Perspectives of Ethnomathematics as a Program (pp. 31-37). ICME-13 Topical Surveys, Berlin: Springer.

Amit, M., \& Qouder, F. A. (2017a). Weaving Culture and Mathematics in the Classroom: The Case of Bedouin Ethnomathematics. In M. Rosa et al. (Eds.), Ethnomathematics and Its Diverse Approaches for Mathematics Education (pp. 23-50). ICME-13 Monographs, Berlin: Springer. https://doi.org/10.1007/978-3-319-59220-6_2

Amit, M., \& Qouder, F. A. (2017b). On the Importance of an Ethnomathematical Curriculum in Mathematics Education. EURASIA Journal of Mathematics, Science and Technology Education, 14, 561-567. https://doi.org/10.12973/ejmste/76956

Amit, M., Fried, M. N., \& Abu-Naja, M. (2007). The Mathematics Club for Excellent Students as Common Ground for Bedouin and Other Israeli Youth. The Montana Mathematics Enthusiast, Monograph, 1, 75-90.

Anderson, S. E. (1990). Worldmath Curriculum: Fighting Eurocentrism in Mathematics. Journal of Negro Education, 59, 348-359. https://doi.org/10.2307/2295569

Ben-Ari, S. (2013). Regulating the Bedouin Settlement in the Negev. Jerusalem: The Knesset, Center for Research and Information. (In Hebrew) https://www.knesset.gov.il/mmm/data/pdf/m03292.pdf

Bishop, A. J. (1994). Cultural Conflicts in Mathematics Education: Developing a Research Agenda. For the Learning of Mathematics, 14, 15-18.

D'Ambrosio, U. (1985). Ethnomathematics and Its Place in the History and Pedagogy of Mathematics. For the Learning of Mathematics, 5, 44-48.

D’Ambrosio, U. (2002). Ethnomathematics: An Overview. In M. de Monteiro (Ed.), Proceedings of Second International Conference on Ethnomathematics (pp. 3-5). Ouro Preto: Lyrium Comunacacao Ltda.

D'Ambrosio, U. (2016). An Overview of the History of Ethnomathematics. In M. Rosa, U. D’Ambrosio, D. C. Orey, L. Shirley et al. (Eds.), Current and Future Perspectives of Ethnomathematics as a Program (pp. 5-10). ICME-13 Topical Surveys, Berlin: Springer. https://doi.org/10.1007/978-3-319-30120-4_2

Gerdes, P. (1997). Survey of Current Work on Ethnomathematics. In A. B. Powel, \& M. Frandenstein (Eds.), Ethnomathematics: Challenging Euroceentrrism in Mathematics Education (pp. 331-371). Albany: State University of New York Press.

Kidumatica for Youth (2017). Kidumatica for Youth-Mathematics Club for Excellence and Creativity-A Description of the Club and Its Goals. Beersheba: Ben-Gurion University of the Negev, Faculty of Humanities and Social Sciences. (In Hebrew) http://in.bgu.ac.il/humsos/kidumatica/Pages/about.aspx

Lawrence, S., \& Palhares, P. (2016). Ethnomathematics and Its Diverse Pedagogical Approaches. In M. Rosa, U. D’Ambrosio, D. C. Orey, L. Shirley, W. V. Alangui, P. Palhares, \& M. E. Gavarrete (Eds.), Current and Future Perspectives of Ethnomathematics 
as a Program (pp. 13-17). ICME-13 Topical Surveys, Berlin: Springer Open.

Massarwe, K., Verner, I., \& Bshouty, D. (2010). An Ethnomathematics Exercise in Analyzing and Constructing Ornaments in a Geometry Class. Journal of Mathematics \& Culture, 5, 1-20.

Maxwell, K. L. H., \& Chahine, I. C. (2013). Cultural Immersion and Mathematics Teacher Education: Explorations in Morocco and South Africa. Journal of Humanistic Mathematics, 3, 62-75. https://doi.org/10.5642/jhummath.201302.04

Myers-JDC-Brookdale (2017). The Bedouins in the Negev: Facts and Figures. Jerusalem: Myers-JDC-Brookdale, The Center for Practical Social Research. (In Hebrew)

Powell, A. B., \& Frankenstein, M. (1997). Ethnomathematics: Challenging Eurocentricism in Mathematics Education. Albany: State University of New York Press.

Shirley, L. (2001). Ethnomathemathematics as a Fundamental of Instructional Methodology. International Reviews on Mathematics Education, 33, 85-87. https://doi.org/10.1007/BF02655699

Rowlands, S., \& Carson, R. N. (2002). Where Would Formal, Academic Mathematics Stand in a Curriculum Informed by Ethnomathematics? A Critical Review of Ethnomathematics. Educational Studies in Mathematics, 50, 79-102. https://doi.org/10.1023/A:1020532926983

Terry, C. L. Sr. (2011). Mathematical Counterstory and African American Male Students: Urban Mathematics Education from a Critical Race Theory Perspective. Journal of Urban Mathematics Education, 1, 23-49.

Verner, I., Massarwe, K., \& Beshouty, D. (2013). Constructs of Engagement Emerging in an Ethnomathematically-Based Teacher Education Course. Journal of Mathematical Behavior, 32, 494-450. https://doi.org/10.1016/j.jmathb.2013.06.002 